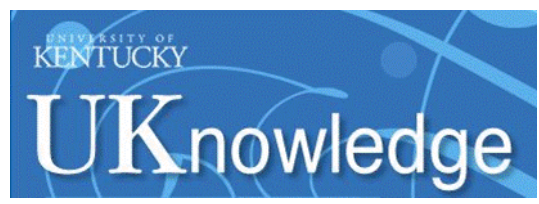

University of Kentucky

UKnowledge

\title{
The Effects of Charge Transfer on the Thermal Equilibrium of Photoionized Nebulae
}

\author{
J. B. Kingdon \\ Oak Ridge National Laboratory \\ Gary J. Ferland \\ University of Kentucky, gary@uky.edu
}

Follow this and additional works at: https://uknowledge.uky.edu/physastron_facpub

Part of the Astrophysics and Astronomy Commons, and the Physics Commons

Right click to open a feedback form in a new tab to let us know how this document benefits you.

\section{Repository Citation}

Kingdon, J. B. and Ferland, Gary J., "The Effects of Charge Transfer on the Thermal Equilibrium of Photoionized Nebulae" (1999). Physics and Astronomy Faculty Publications. 113.

https://uknowledge.uky.edu/physastron_facpub/113

This Article is brought to you for free and open access by the Physics and Astronomy at UKnowledge. It has been accepted for inclusion in Physics and Astronomy Faculty Publications by an authorized administrator of UKnowledge. For more information, please contact UKnowledge@lsv.uky.edu. 


\title{
The Effects of Charge Transfer on the Thermal Equilibrium of Photoionized Nebulae
}

\author{
Digital Object Identifier (DOI) \\ http://dx.doi.org/10.1086/312008 \\ Notes/Citation Information \\ Published in The Astrophysical Journal Letters, v. 516, no. 2, p. L107-L109. \\ (C) 1999. The American Astronomical Society. All rights reserved. Printed in the U.S.A. \\ The copyright holder has granted permission for posting the article here.
}




\title{
THE EFFECTS OF CHARGE TRANSFER ON THE THERMAL EQUILIBRIUM OF PHOTOIONIZED NEBULAE
}

\author{
J. B. KINGDON \\ Physics Division, Oak Ridge National Laboratory, P.O. Box 2008, Oak Ridge, TN 37831 \\ AND \\ G. J. FERLAND \\ Department of Physics and Astronomy, University of Kentucky, Lexington, KY 40506 \\ Received 1999 February 1; accepted 1999 March 5; published 1999 March 15
}

\begin{abstract}
Charge transfer can affect both the ionization and thermal balance of astrophysical plasmas. Using the most recent rate coefficients and energy defects, we calculate the heating/cooling rates for charge transfer reactions between hydrogen and elements up to $Z=30$. We incorporate these values into the photoionization code CLOUDY. Results from models approximating a wide range of astrophysical objects and conditions suggest that charge transfer can make a significant contribution to the heating near the $\mathrm{H}$ ionization front, particularly in objects with a hard ionizing continuum or enhanced abundances. Charge transfer heating can also be important in regimes in which the usual heating/cooling agents are suppressed, such as the emission-line clouds near quasars. We list those reactions that are most important for determining the thermal balance, in the hopes of facilitating improved atomic data.
\end{abstract}

Subject headings: atomic data - atomic processes

\section{INTRODUCTION}

An accurate understanding of the emergent spectra of emission-line objects requires detailed modeling of the atomic and molecular processes affecting conditions in the gas. While such processes as collisional excitation and photoionization have long been incorporated into nebular models, charge transfer reactions of the type

$$
\mathrm{X}^{+q}+\mathrm{H} \rightarrow \mathrm{X}^{+(q-1)}+\mathrm{H}^{+}+\Delta E
$$

have received somewhat less attention. The reasons for this are twofold. First, until relatively recently, accurate rate coefficients were available only for a small number of reactions at temperatures typical of astrophysical plasmas. Second, unlike radiative recombination, charge transfer is highly state specific. That is, depending on the ions involved, a given reaction may have several, one, or no accessible channels.

Several researchers have discussed the importance of charge transfer reactions for calculating line emissivities and determining the ionization balance of astrophysical plasmas (see Field \& Steigman 1971; Williams 1973; Baliunas \& Butler 1980; Péquignot 1980; Dalgarno \& Sternberg 1982; Shields, Dalgarno, \& Sternberg 1983; Allan et al. 1988). Far less work, however, has been done on the thermal effects of charge transfer. Kinetic energy can be gained or lost during the exchange, depending on the specific states involved. Kallman \& McCray (1982) included charge transfer heating in models of gas illuminated by X-rays. However, since the thermal balance in their models was dominated by Compton heating and bremsstrahlung cooling, they did not explicitly discuss the detailed effects of charge transfer heating.

In light of a significant increase in the number of reactions for which accurate data are available, we feel that it is important to address in detail the issue of charge transfer heating. In $\S 2$, we describe the basic concepts and the incorporation of the data into the CLOUDY photoionization code (Ferland et al. 1998). In $\S 3$, we discuss general and specific results obtained from a number of astrophysical models.

\section{ATOMIC DATA}

In this Letter, heating and cooling are measured with respect to the continuum rather than to the ground state. In this system, the energy gained or lost per unit volume per unit time for reaction (1) is simply equal to $n_{\mathrm{H}} n_{\mathrm{X}^{+q}} \alpha_{\mathrm{CT}} \Delta E$, where the $n$ 's are the densities of the parent ions, $\alpha_{\mathrm{CT}}$ is the rate coefficient for the reaction, and $\Delta E$ is the energy defect, either positive or negative, depending on the reaction. We therefore need to obtain $\alpha_{\mathrm{CT}}$ and $\Delta E$.

Fits as a function of temperature to rate coefficients for reactions between $\mathrm{H}$ and all ions with charge $q=1-4$ up to $Z=30$ are given in Kingdon \& Ferland (1996 and updates and addenda). ${ }^{1}$ These sources also list fits for reactions between several atoms and $\mathrm{H}^{+}$, the reverse of equation (1). For ions with charge $q>4$, we use the Langevin rate coefficients of Ferland et al. (1997). These data are already stored in CLOUDY's database. In all of these reactions, we assume that interstellar conditions apply, namely, that both reactants are in their ground state. Therefore, reverse reactions involving excited states cannot be important.

The determination of the energy defects requires a bit more discussion. As mentioned in $\S 1$, for some reactions, there are several levels of the recombined ion into which the electron can transfer. Unfortunately, most sources of charge transfer rate coefficients do not give state-specific data, but only total rate coefficients. While it is our eventual goal to input all statespecific data into CLOUDY, for the purpose of this Letter we shall only utilize total rate coefficients. Thus, for reactions having multiple channels, we must use mean energy defects. For those reactions for which state-specific results are available from the literature, the mean energy defects are derived directly from the individual $\Delta E$ 's for each channel. For reactions for which no state-specific data exist, we make use of the fact that for charge transfer involving only one electron, one obtains large rate coefficients only for channels having avoided crossings between roughly 7 and 13 bohr (see Neufeld \& Dalgarno

\footnotetext{
${ }^{1}$ Updates and addenda are listed at http://www-cfadc.phy.ornl.gov/astro/jk/ ct.html.
} 
TABLE 1

Energy Defects for Charge Transfer Recombination

\begin{tabular}{|c|c|c|c|c|c|c|c|}
\hline Ion & $\begin{array}{c}\Delta E \\
(\mathrm{eV})\end{array}$ & Ion & $\begin{array}{c}\Delta E \\
(\mathrm{eV})\end{array}$ & Ion & $\begin{array}{c}\Delta E \\
(\mathrm{eV})\end{array}$ & Ion & $\begin{array}{c}\Delta E \\
(\mathrm{eV})\end{array}$ \\
\hline $\mathrm{He}^{+}$ & 10.99 & $\mathrm{He}^{+2}$ & 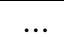 & $\ldots$ & $\ldots$ & $\ldots$ & $\ldots$ \\
\hline $\mathrm{Li}^{+}$ & $\ldots$ & $\mathrm{Li}^{+2}$ & 3.02 & $\mathrm{Li}^{+3}$ & $\ldots$ & $\ldots$ & $\cdots$ \\
\hline $\mathrm{Be}^{+}$ & $\ldots$ & $\mathrm{Be}^{+2}$ & $\ldots$ & $\mathrm{Be}^{+3}$ & $\ldots$ & $\mathrm{Be}^{+4}$ & 10.59 \\
\hline $\mathrm{B}^{+}$. & $\ldots$ & $\mathrm{B}^{+2}$ & 2.46 & $\mathrm{~B}^{+3}$ & $\ldots$ & $\mathrm{B}^{+4}$ & 11.00 \\
\hline $\mathrm{C}^{+}$ & -2.34 & $\mathrm{C}^{+2}$ & 4.01 & $\mathrm{C}^{+3}$ & 5.73 & $\mathrm{C}^{+4}$ & 11.30 \\
\hline $\mathrm{N}^{+}$ & 0.94 & $\mathrm{~N}^{+2}$ & 4.56 & $\mathrm{~N}^{+3}$ & 6.40 & $\mathrm{~N}^{+4}$ & 11.00 \\
\hline $\mathrm{O}^{+}$ & 0.02 & $\mathrm{O}^{+2}$ & 6.65 & $\mathrm{O}^{+3}$ & 5.00 & $\mathrm{O}^{+4}$ & 8.47 \\
\hline $\mathrm{F}^{+}$ & $\ldots$ & $\mathrm{F}^{+2}$ & $\ldots$ & $\mathrm{F}^{+3}$ & 5.60 & $\mathrm{~F}^{+4}$ & 11.80 \\
\hline $\mathrm{Ne}^{+}$ & $\ldots$ & $\mathrm{Ne}^{+2}$ & $\ldots$ & $\mathrm{Ne}^{+3}$ & 5.82 & $\mathrm{Ne}^{+4}$ & 8.60 \\
\hline $\mathrm{Na}^{+}$ & $\ldots$ & $\mathrm{Na}^{+2}$ & $\ldots$ & $\mathrm{Na}^{+3}$ & 6.25 & $\mathrm{Na}^{+4}$ & 11.00 \\
\hline $\mathrm{Mg}^{+} \ldots \ldots$ & $\ldots$ & $\mathrm{Mg}^{+2} \ldots \ldots$ & 1.44 & $\mathrm{Mg}^{+3}$ & 5.73 & $\mathrm{Mg}^{+4}$ & 8.60 \\
\hline $\mathrm{Al}^{+} \ldots \ldots$ & $\ldots$ & $\mathrm{Al}^{+2} \ldots \ldots$ & $\ldots$ & $\mathrm{Al}^{+3}$ & 8.17 & $\mathrm{Al}^{+4}$ & 8.00 \\
\hline $\mathrm{Si}^{+}$ & $\ldots$ & $\mathrm{Si}^{+2}$ & 2.72 & $\mathrm{Si}^{+3}$ & 4.23 & $\mathrm{Si}^{+4}$ & 7.49 \\
\hline $\mathrm{P}^{+}$. & $\ldots$ & $\mathrm{P}^{+2}$ & 3.45 & $\mathrm{P}^{+3}$ & 7.29 & $\mathrm{P}^{+4}$ & 9.71 \\
\hline $\mathrm{S}^{+}$ & -3.24 & $\mathrm{~S}^{+2}$ & $\ldots$ & $\mathrm{S}^{+3}$ & 5.73 & $\mathrm{~S}^{+4}$ & 8.60 \\
\hline $\mathrm{Cl}^{+} \ldots \ldots$ & $\ldots$ & $\mathrm{Cl}^{+2}$ & $\ldots$ & $\mathrm{Cl}^{+3}$ & 8.00 & $\mathrm{Cl}^{+4}$ & 9.00 \\
\hline $\mathrm{Ar}^{+}$ & $\ldots$ & $\mathrm{Ar}^{+2}$ & .. & $\mathrm{Ar}^{+3}$ & 5.73 & $\mathrm{Ar}^{+4}$ & 8.60 \\
\hline $\mathrm{K}^{+}$. & $\ldots$ & $\mathrm{K}^{+2}$. & $\ldots$ & $\mathrm{K}^{+3}$. & 6.00 & $\mathrm{~K}^{+4}$. & $\ldots$ \\
\hline $\mathrm{Ca}^{+}$ & $\ldots$ & $\mathrm{Ca}^{+2}$ & $\ldots$ & $\mathrm{Ca}^{+3}$ & 6.60 & $\mathrm{Ca}^{+4}$ & 9.90 \\
\hline $\mathrm{Sc}^{+}$. & $\ldots$ & $\mathrm{Sc}^{+2}$ & $\ldots$ & $\mathrm{Sc}^{+3}$ & 3.50 & $\mathrm{Sc}^{+4}$. & 10.61 \\
\hline $\mathrm{Ti}^{+} \ldots \ldots$ & $\ldots$ & $\mathrm{Ti}^{+2}$ & $\cdots$ & $\mathrm{Ti}^{+3}$ & 4.30 & $\mathrm{Ti}^{+4}$ & 5.30 \\
\hline $\mathrm{V}^{+} \ldots$ & $\ldots$ & $\mathrm{V}^{+2}$ & $\ldots$ & $\mathrm{V}^{+3}$ & 4.70 & $\mathrm{~V}^{+4}$ & 6.20 \\
\hline $\mathrm{Cr}^{+}$. & $\ldots$ & $\mathrm{Cr}^{+2}$ & 2.89 & $\mathrm{Cr}^{+3}$ & 5.40 & $\mathrm{Cr}^{+4}$ & 6.60 \\
\hline $\mathrm{Mn}^{+}$. & $\ldots$ & $\mathrm{Mn}^{+2}$ & 2.04 & $\mathrm{Mn}^{+3}$ & 6.00 & $\mathrm{Mn}^{+4}$ & 7.00 \\
\hline $\mathrm{Fe}^{+} \ldots$ & $\ldots$ & $\mathrm{Fe}^{+2}$ & 2.56 & $\mathrm{Fe}^{+2}$ & 6.30 & $\mathrm{Fe}^{+4}$ & 10.00 \\
\hline $\mathrm{Co}^{+}$ & $\ldots$ & $\mathrm{Co}^{+2}$ & 2.90 & $\mathrm{Co}^{+3}$ & 6.00 & $\mathrm{Co}^{+4}$ & 10.51 \\
\hline $\mathrm{Ni}^{+} \ldots \ldots$ & $\ldots$ & $\mathrm{Ni}^{+2}$ & 3.00 & $\mathrm{Ni}^{+3}$ & 5.20 & $\mathrm{Ni}^{+4}$ & 10.0 \\
\hline $\mathrm{Cu}^{+} \ldots \ldots$ & $\ldots$ & $\mathrm{Cu}^{+2} \ldots$. & 3.44 & $\mathrm{Cu}^{+3}$ & 5.60 & $\mathrm{Cu}^{+4} \ldots \ldots$ & 9.00 \\
\hline $\mathrm{Zn}^{+} \ldots \ldots$ & $\ldots$ & $\mathrm{Zn}^{+2} \ldots \ldots$ & $\ldots$ & $\mathrm{Zn}^{+3} \ldots \ldots$ & 7.80 & $\mathrm{Zn}^{+4} \ldots \ldots$ & 11.73 \\
\hline
\end{tabular}

1987). Then, by assuming a mean avoided crossing distance of $9.5 \mathrm{bohr}$, we can, to a good approximation, derive mean energy defects that depend only on the parent ion charge $q$. This same method is applied to the Langevin rates of Ferland et al. (1997). The energy defects determined in this manner should generally be accurate to much better than $50 \%$.

For some reactions, no significant channel exists. In these cases, charge transfer can proceed through the emission of a photon (Butler, Guberman, \& Dalgarno 1977). While the energy of this photon is strongly peaked at the difference in ionization energies between the initial and final state of the transferred electron, some partitioning of energy exists, resulting in a continuous spectrum (see Stancil \& Zygelman 1996). The effects of this radiative charge transfer are thus difficult to properly model. However, because of the very small rate coefficients of this process $\left(\sim 10^{-14} \mathrm{~cm}^{3} \mathrm{~s}^{-1}\right.$; see Butler et al. 1977), its effect on our results should be negligible, and thus we have not included it here.

If charge transfer occurs to the ground state of the recombined ion, the nebular physics involved is fairly straightforward since no radiation is produced. If, however, the transfer occurs into an excited state, additional photons are produced. Although

TABLE 2

Energy Defects for Charge Transfer IONIZATION

\begin{tabular}{cr|cr}
\hline \hline \multicolumn{1}{c|}{ Ion } & $\begin{array}{c}\Delta E \\
(\mathrm{eV})\end{array}$ & \multicolumn{1}{c}{ Ion } & $\begin{array}{c}\Delta E \\
(\mathrm{eV})\end{array}$ \\
\hline $\mathrm{Li}^{0} \ldots \ldots \ldots$ & $\ldots$ & $\mathrm{Si}^{0} \ldots \ldots \ldots$ & 0.12 \\
$\mathrm{C}^{0} \ldots \ldots \ldots$ & 2.34 & $\mathrm{Si}^{+} \ldots \ldots \ldots$ & -2.72 \\
$\mathrm{~N}^{0} \ldots \ldots \ldots$ & -0.94 & $\mathrm{~S}^{0} \ldots \ldots \ldots$ & $\ldots$ \\
$\mathrm{O}^{0} \ldots \ldots \ldots$ & -0.02 & $\mathrm{Cr}^{+} \ldots \ldots$ & -2.89 \\
$\mathrm{Na}^{0} \ldots \ldots$ & -1.74 & $\mathrm{Mn}^{+} \ldots \ldots$ & -2.04 \\
$\mathrm{Mg}^{0} \ldots \ldots$ & 1.52 & $\mathrm{Fe}^{+} \ldots \ldots$. & -2.56 \\
$\mathrm{Mg}^{+} \ldots \ldots$ & -1.44 & $\mathrm{Co}^{+} \ldots \ldots$ & -3.49 \\
\hline
\end{tabular}

any photons emitted in a radiative cascade to the ground state are not counted in the thermal balance in our system of bookkeeping, they will contribute to the diffuse field and may be capable of ionizing $\mathrm{H}$. These diffuse photons will in most cases be negligible, and we do not consider them here.

Additional complications arise at very high densities. If, after transfer to an excited state, the atom is collisionally excited or de-excited, rather than radiatively decaying, our calculated energy defects must be modified. However, as discussed in the next section, reactions between $\mathrm{H}$ and singly or doubly ionized ions yield the maximum percentage charge transfer heating. The only astrophysically important ions for which transfer occurs to an excited state are $\mathrm{C}^{+2}, \mathrm{~N}^{+2}$, and $\mathrm{O}^{+2}$. Some statespecific information is available for all of these ions. In all three cases, the predominant reaction channel involves transfer into a level that can resonantly decay to the ground state of the recombined ion. The critical densities (the densities at which the collisional de-excitation rate equals the radiative rate) for these levels are on the order of $\sim 10^{15} \mathrm{~cm}^{-3}$, many orders of magnitude larger than the densities found in gaseous nebulae. Thus, neglect of these collisional processes should have a negligible effect on our results.

For completeness, we list in Table 1 the energy defects adopted here for charge transfer recombination reactions involving ions with $q \leq 4$. For ions with higher charge, we use a mean energy defect equal to $2.86 q \mathrm{eV}$, based on the discussion above. Energy defects for charge transfer ionization reactions are given in Table 2. In most cases, null entries in these tables correspond to ions for which the reactions proceed by radiative charge transfer.

\section{RESULTS}

Using the energy defects given in Tables 1 and 2, we have modified the spectral synthesis code CLOUDY to include the 
effects of charge transfer heating/cooling in its calculation of thermal balance. This is included in versions 90.05 and later of the code. In order to examine the importance of charge transfer heating/cooling in a wide range of astrophysical environments, we have run numerous models, including several from the CLOUDY test suite (Ferland 1996). These include a planetary nebula, the Orion nebula, an old nova shell, a narrowline region, and a broad-line region.

Although the nature of charge transfer heating/cooling and its relative importance to the thermal balance will depend strongly on the physical parameters, we have been able to glean several general points from our model runs:

1. Charge transfer is primarily a heating mechanism. That this is the case is easily verified by a cursory examination of Tables 1 and 2, which shows that the vast majority of the reactions are exothermic.

2. The effect is strongly localized in the $\mathrm{H} / \mathrm{H}^{+}$transition zone. This is because charge transfer involves species of different ionization potentials, so that there is usually a relatively small region in which the reactants coexist in significant numbers.

3. The relative importance of charge transfer to the total heating increases with harder ionizing continua. As the radiation field hardens, more highly charged species can coexist with neutral $\mathrm{H}$. Because charge transfer reactions between such ions and $\mathrm{H}$ generally have both larger rate coefficients and larger energy defects, the contribution of charge transfer to the resulting thermal equilibrium is increased.

4. Charge transfer reactions can be very important in determining the thermal balance in situations in which the normal heating/cooling agents are suppressed. For example, the charge transfer heating rate easily reaches $10 \%-20 \%$ of the heating in BLR clouds such as those modeled in Ferland et al. (1996). Our tests indicate that under these circumstances, charge transfer heating is dominated by reactions involving ions with low charge.

As an example, we present a model of a nova shell in which the thermal effects of charge transfer are very important. The model consists of gas at a density of $3 \times 10^{8} \mathrm{~cm}^{-3}$, located a distance of $3 \times 10^{15} \mathrm{~cm}$ from the ionizing source, which is taken to be a blackbody with a temperature $T=1.25 \times 10^{5}$ $\mathrm{K}$ and a luminosity equal to $10^{38} \mathrm{ergs} \mathrm{s}^{-1}$. The abundances of the elements are solar, with the exception of $\mathrm{N}$ and $\mathrm{O}$, which are taken to be 100 and 10 times solar, respectively, as is typical of novae (see the extensive reviews presented in Howell, Kuulkers, \& Woodward 1998).

Figure 1 depicts the fraction of the local heating due to charge transfer reactions as a function of depth for this model. This fraction reaches a maximum of $\sim 60 \%$, dominated by the reaction $\mathrm{N}^{+}+\mathrm{H} \rightarrow \mathrm{N}+\mathrm{H}^{+}$. The minimum fraction obtained is $\sim 1 \%$.

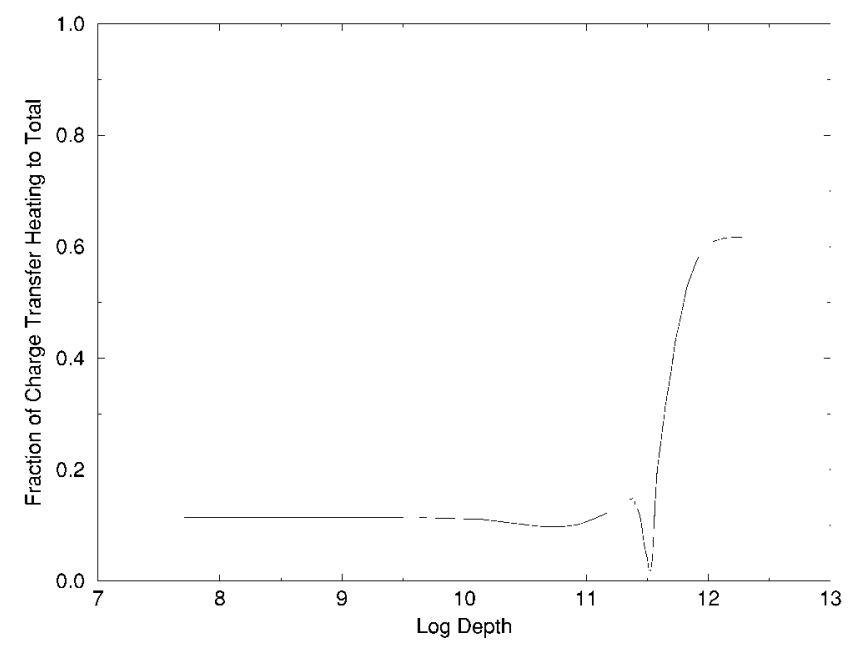

FIG. 1.-Fraction of heating due to charge transfer vs. depth for the model discussed in the text.

The results of this Letter indicate that charge transfer reactions can play a significant role in determining the thermal balance of many nebulae, both locally and globally. It is therefore imperative to have accurate state-specific values of the rate coefficients and energy defects. From our tests, we find that the most important reactions are $\mathrm{C}^{+2}, \mathrm{C}^{+3}, \mathrm{~N}^{+}, \mathrm{O}^{+}$, and $\mathrm{O}^{+2}$ reacting with $\mathrm{H}$, and $\mathrm{O}^{0}$ reacting with $\mathrm{H}^{+}$. Quantal calculations exist for all of these reactions, so that the rate coefficients should be fairly reliable. The state of affairs for the two oxygen reactions has been heretofore less than ideal (Kingdon \& Ferland 1996). New quantal calculations covering a temperature range more appropriate for astrophysical plasmas are in preparation. Preliminary results (P. C. Stancil 1998, private communication) give rate coefficients at $10,000 \mathrm{~K}$ that are $\sim 80 \%$ larger than those used here, increasing the importance of these reactions.

The authors acknowledge useful discussions with P. C. Stancil, C. Knigge, E. R. Capriotti, and K. MacAdam. This research was supported in part by the Office of Fusion Energy Sciences, US Department of Energy, under contract DE-AC0596OR22464 with Lockheed Martin Energy Research Corp. and by an appointment for J. B. K. to the Oak Ridge National Laboratory (ORNL) Postdoctoral Research Associates Program administered jointly by ORNL and by the Oak Ridge Institute for Science and Education. CLOUDY has been generously supported by the National Science Foundation and NASA. G. J. F. would like to thank the Canadian Institute for Theoretical Astrophysics for their hospitality during his visit.

\section{REFERENCES}

Allan, R. J., Clegg, R. E. S., Dickinson, A. S., \& Flower, D. R. 1988, MNRAS, 235,1245

Baliunas, S. L., \& Butler, S. E. 1980, ApJ, 235, L45

Butler, S. E., Guberman, S. L., \& Dalgarno, A. 1977, Phys. Rev. A, 16, 500

Dalgarno, A., \& Sternberg, A. 1982, ApJ, 257, L87

Ferland, G. J. 1996, Hazy, a Brief Introduction to CLOUDY 90, Univ. of Kentucky Physics Department Internal Report

Ferland, G. J., et al. 1996, ApJ, 461, 683

Ferland, G. J., Korista, K. T., Verner, D. A., \& Dalgarno, A. 1997, ApJ, 481, L115

Ferland, G. J., Korista, K. T., Verner, D. A., Ferguson, J. W., Kingdon, J. B., \& Verner, E. M. 1998, PASP, 110, 761
Field, G. B., \& Steigman, G. 1971, ApJ, 166, 59

Howell, S., Kuulkers, E., \& Woodward, C., ed. 1998, ASP Conf. Ser. 137, Wild Stars in the Old West: Proceedings of the 13th North American Workshop on Cataclysmic Variables and Related Objects (San Francisco: ASP) Kallman, T. R., \& McCray, R. 1982, ApJS, 50, 263

Kingdon, J. B., \& Ferland, G. J. 1996, ApJS, 106, 205

Neufeld, D. A., \& Dalgarno, A. 1987, Phys. Rev. A, 35, 3142

Péquignot, D. 1980, A\&A, 81, 356

Shields, G. A., Dalgarno, A., \& Sternberg, A. 1983, Phys. Rev. A, 28, 2137

Stancil, P. C., \& Zygelman, B. 1996, ApJ, 472, 102

Williams, R. E. 1973, MNRAS, 164, 111 